\title{
Are there any disturbances in vestibular organ of children and young adults with Type I diabetes?
}

\author{
W. Gawron ${ }^{1}$, L. Pospiech ${ }^{1}$, K. Orendorz-Fraczkowska ${ }^{1}$, A. Noczynska ${ }^{2}$ \\ ${ }^{1}$ ENT Department Faculty of Medicine, ${ }^{2}$ Faculty of Medicine Department of Endocrinology for Children and Adolescents, \\ University of Wroclaw, Wroclaw, Poland
}

\section{Abstract}

Aims/hypothesis. The aim of the work was to evaluate the vestibular organ condition in children and young adults suffering from Type I (insulin-dependent) diabetes mellitus.

Methods. The group examined consisted of 95 children and young adults aged from 6 to 28 years with Type I diabetes diagnosed. The diabetic group was divided into subgroups according to duration of the disease, compensation of the disease, and presence and character of hypoglycaemic incidents, and presence of diabetic complications. The control group consisted of 44 healthy children and young adults aged 6 to 28 years. After collecting detailed medical history in each case an electronystagmographic test was performed using the computed two-canal electronystagmographer.

Results. Within the diabetic group 6 patients complained about vertigo and balance disorders. Sponta- neous nystagmus occurred in 10 cases, positional one in 21 cases. Impaired optokinesis occurred in 36 cases and impaired eye tracking test in 33 cases. In caloric tests there was partial canal paresis in 4 cases and directional preponderance in 7 cases.

Conclusion/interpretation. Metabolic disturbances present in Type I diabetes cause disturbances in different parts of vestibular organ but mostly in its central part. Comparing disturbances in the vestibular organ with clinical and biochemical parameters characterising diabetes, the range of vestibular organ impairment in diabetes mellitus type 1 seems to depend mainly on the presence and character of hypoglycaemic incidents and the duration of the disease and to some extent on the compensation of diabetes. [Diabetologia (2002) 45:728-734]

Keywords Diabetes mellitus Type I, children, vertigo, vestibular organ.
Diabetic neuropathy encompasses various disturbances of the somatic and autonomic nervous system and has a serious impact on prognosis and morbidity in diabetes mellitus [1]. The incidence of neuropathy varies from $7 \%$ in patients suffering for one year to $50 \%$ in patients suffering for 25 years. If one also considers patients with subclinical neuropathy the inci-

Received: 8 November 2001 / Revised: 28 January 2002 Published online: 17 April 2002

(C) Springer-Verlag 2002

Corresponding author: Dr. W. Gawron, ul. Krzycka 32, 53-020 Wroclau, Poland, e-mail: wgawron@interia.pl Abbreviations: BEAP, Brain Evoked Auditory Potentials; ENG, electronystagmography dence can rise to $90 \%$ [2, 3]. It was Jordao who in 1857 noticed a connection between hearing loss and diabetes mellitus in a patient with diabetic coma (acc. to [3]). Within the compass of years many authors proved different kinds of inner ear impairment, both in humans as well as in animals with diabetes induced experimentally $[3,4,5,6,7]$. There are sparse and often inconsistent data concerning the influence of different metabolic disturbances present in diabetes on vestibular organ. No literature concerning vestibular organ condition in children with diabetes mellitus has been found.

We aimed to evaluate the vestibular organ condition in children and young adults suffering from Type I diabetes and attempted to answer the question whether disturbances present in vestibular organ can 
be connected with clinical and biochemical parameters characterising diabetes mellitus.

\section{Materials and methods}

The group examined consisted of 95 children and young adults (51 females and 44 males) aged from 6 to 28 years (mean age 15.5 years; SD 5.1] diagnosed with Type I diabetes. Patients with any events which had potential influence on auditory or vestibular organ or both as well as patients with any local pathology within ENT organs which had negative influence on the inner ear were excluded from the tests. All the patients had intensive insulin therapy, in two cases with the use of infusion pumps. The duration of the disease varied from 0.5 to 22 years [5.95 years on average]. The group was divided into subgroups according to the duration of the disease, compensation of the disease (blood concentration of glycated haemoglobin), presence and character of hypoglycaemic incidents, and presence of diabetic complications. The subgroup with complications [22 patients] encompassed those subjects who, on the basis of routine tests, had retinopathy, nephropathy or polyneuropathy. The control group consisted of 44 healthy subjects 24 males and 20 females] aged from 6 to 28 years (mean age 16.3 years, SD 6.1).

Detailed medical history concerning diabetes mellitus and other disturbances which could affect the inner ear was collected in each case. Physical examination, pure tone audiometry, tympanometry and brain evoked auditory potentials (BEAP) were done in each case. Glycated haemoglobin blood concentration with the use of the Abbott IM Glycated Haemoglobin Assay was measured on the day of examination in each diabetic case. To evaluate vestibular organ condition primarily detailed medical history was collected. In the second step, standard physical examination of vestibular organ was done. Then electronystagmographic test was done in each case with the use of computed two-canal electronystagmographer produced by Hortmann. Electronystagmographic registration consisted of the presence of spontaneous nystagmus with eyes opened in sitting position; the presence of spontaneous nystagmus with eyes closed in sitting position; and then the presence and character of positional nystagmus with eyes closed in 4 other positions: lying on the back, on the right side, on the left side, and Rose position (lying on the back with the head deflected backwards) was evaluated. The classification of the nystagmus was done according to Nylen. Then evaluation of optokinetic nystagmus to the right and left with stripes' speed of $10 \%$ s was made based on the gain values and symmetry of the reaction. The response was interpreted as proper or improper.

The next step was to perform eye tracking test with lighting point moving in to the right and left with the speed of $10 \%$ s.

As the last point caloric stimulation according to FitzgeraldHallpike procedure was carried out.

To make calculations according to the Jongkees formula, the computer analysed the frequency of nystagmoidal eye balls movements in the chosen period of $30 \mathrm{~s}$. For statistical analysis computer program SPSS was applied. A $p$ value of less than 0.05 was considered to be statistically significant.

\section{Results}

None of the 44 persons belonging to the Control Group had any complaints connected to hearing or vestibular organ pathology. Physical ENT examina-

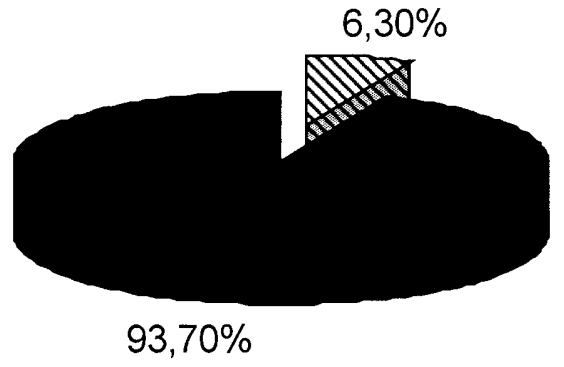

Fig. 1. Complaints of vertigo in diabetic patients

tion did not reveal any important pathology. In pure tone audiometry the response for air and bone conduction was normal in all the cases. There was tympanogram type $\mathrm{A}$ in impedance audiometry in all the cases. None of the patients with diabetes had any complaints connected to hearing acuity. Six patients, with only one child among them, $(6.3 \%)$ complained about vertigo and balance disorders (Fig. 1).

Physical ENT examination revealed nasal septum deviation in 11 cases [11.6\%]. In comparison to the control group there was an increase in average threshold values for air and bone conduction (10 dB nHL) in pure tone audiometry in patients with diabetes. There was tympanogram type A in impedance audiometry in all the cases with mono or bilateral lack of stapedial muscle reflex in 11 cases (11.6\%). In BEAP peak latencies of I wave were prolonged $(p<0.001)$ in diabetic patients as compared to healthy subjects. Moreover there were peak $\mathrm{V}$ and interpeak I-III latencies prolonged in the subjects with diabetic complications. Despite longer average duration of the disease in girls and women, diabetic females presented lower values of BAEP parameters than males. We have not found any correlation between BAEP latencies and duration or the level of compensation of diabetes.

ENG results in the Control and Diabetic Group are presented in the Table 1. Spontaneous nystagmus with eyes closed occurred markedly in patients with diabetes lasting for at least ten years. The analysis of positional nystagmus showed considerable increase in disturbances in the subgroups with longer history of the disease (Table 2).

The percentage of disturbances in optokinetic response increased markedly in subgroups with longer history of the disease (Fig. 2).

There were not any important changes in eye tracking test, evaluated according to the duration of the disease. Slow-phase velocity of nystagmus induced in caloric test was analysed. There was no distinct increase of slow phase velocity for stimulation with water of temperature $30^{\circ} \mathrm{C}$ in the subgroup with diabetes lasting up to 5 years and then a considerable decrease of the velocity in the subgroups with disease lasting longer than five years (Fig. 3).

There were no considerable changes in the occurrence of spontaneous nystagmus in the test with eyes 
Table 1. Electronystagmographic results in diabetic and control group

\begin{tabular}{|c|c|c|}
\hline Parameter evaluated & $\begin{array}{l}\text { Control Group } \\
n=44\end{array}$ & $\begin{array}{l}\text { Diabetic Group } \\
n=95\end{array}$ \\
\hline Spontaneous nystagmus & Absent & $10(11 \%)$ \\
\hline Positional nystagmus & $\begin{array}{l}\text { Nylen I - } 1 \\
(0.02 \%) \\
\text { Nylen II - nb } \\
\text { Nylen III - nb }\end{array}$ & $\begin{array}{l}\text { Nylen I - 5 } \\
(5.26 \%) \\
\text { Nylen II - } 6 \\
(6.31 \%) \\
\text { Nylen III - } 10 \\
(10.5 \%)\end{array}$ \\
\hline Impaired optokinesis & $3(6.8 \%)$ & $36(37.9 \%)$ \\
\hline Impaired eye tracking test & $2(4.55 \%)$ & $33(34.7 \%)$ \\
\hline $\mathrm{SPV} 44^{\circ}$ & $\begin{array}{l}8.16 \% / \mathrm{s} \\
(\mathrm{SD} 4.68)\end{array}$ & $\begin{array}{l}12.36^{\circ} / \mathrm{s} \\
(\mathrm{SD} 8.26)\end{array}$ \\
\hline $\mathrm{SPV} 30^{\circ}$ & $\begin{array}{l}15.04^{\circ} / \mathrm{s} \\
(\mathrm{SD} 6.57)\end{array}$ & $\begin{array}{l}16.76^{\circ} / \mathrm{s} \\
(\mathrm{SD} 8.63)\end{array}$ \\
\hline $\mathrm{CP}$ & $\begin{array}{l}\text { Symmetry - } 44 \\
(100 \%)\end{array}$ & $\begin{array}{l}\text { Asymmetry } 4 \\
(4.22 \%)\end{array}$ \\
\hline DP & $2(4.54 \%)$ & $7(7.36 \%)$ \\
\hline
\end{tabular}

$S P V$ Slow phase velocity, $C P$ Canal paresis, $D P$ Directional preponderance

Table 2. Relation between positional nystagmus and the duration of diabetes

\begin{tabular}{lllll}
\hline $\begin{array}{l}\text { Type of } \\
\text { nystagmus }\end{array}$ & \multicolumn{2}{l}{$\%$ of disturbances } \\
\cline { 2 - 5 } & $\begin{array}{l}\text { Till 1 year } \\
n=22\end{array}$ & $\begin{array}{l}\text { 1 to 5 years } \\
n=30\end{array}$ & $\begin{array}{l}5 \text { to 10 years } \\
n=22\end{array}$ & $\begin{array}{l}>10 \text { years } \\
n=21\end{array}$ \\
\hline Nylen I & - & - & $9.1 \%$ & $14.3 \%$ \\
Nylen II & - & - & - & $28.6 \%$ \\
Nylen III & $4.5 \%$ & $3.3 \%$ & $18.2 \%$ & $19 \%$ \\
Together & $4.5 \%$ & $3.3 \%$ & $27.3 \%$ & $61.9 \%$ \\
& & & & $p<0.01$ \\
\hline
\end{tabular}

Table 3. Relation between positional nystagmus and compensation of diabetes

\begin{tabular}{|c|c|c|c|c|}
\hline \multirow{2}{*}{$\begin{array}{l}\text { Type of } \\
\text { nystagmus }\end{array}$} & \multicolumn{4}{|c|}{ Compensation of diabetes $\left(\mathrm{HgbA}_{1} \mathrm{C}\right.$ level $)$} \\
\hline & $\begin{array}{l}\text { Well } \\
(4.4 \%-6.4 \%) \\
n=13\end{array}$ & $\begin{array}{l}\text { Moderately } \\
(6.5 \%-8.4 \%) \\
n=39\end{array}$ & $\begin{array}{l}\mathrm{Bad} \\
(8.5 \%-10.0 \%) \\
n=28\end{array}$ & $\begin{array}{l}\text { Not } \\
\text { comp. } \\
(>10 \%) \\
n=15\end{array}$ \\
\hline Nylen I & - & $5.1 \%$ & $7.1 \%$ & $6.7 \%$ \\
\hline Nylen II & - & $10.3 \%$ & $7.1 \%$ & - \\
\hline Nylen III & $7.6 \%$ & $15.4 \%$ & $10.7 \%$ & - \\
\hline Together & $7.6 \%$ & $30.8 \%$ & $24.9 \%$ & $6.7 \%$ \\
\hline
\end{tabular}

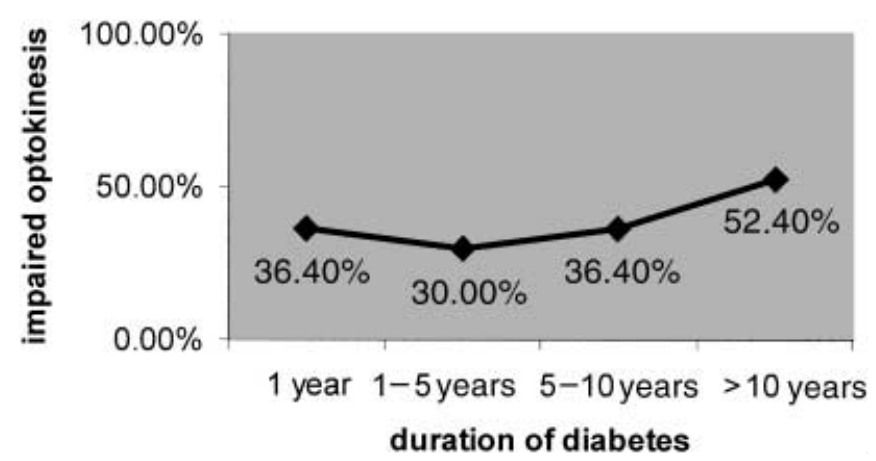

Fig. 2. Relation between optokinetic response and duration of diabetes

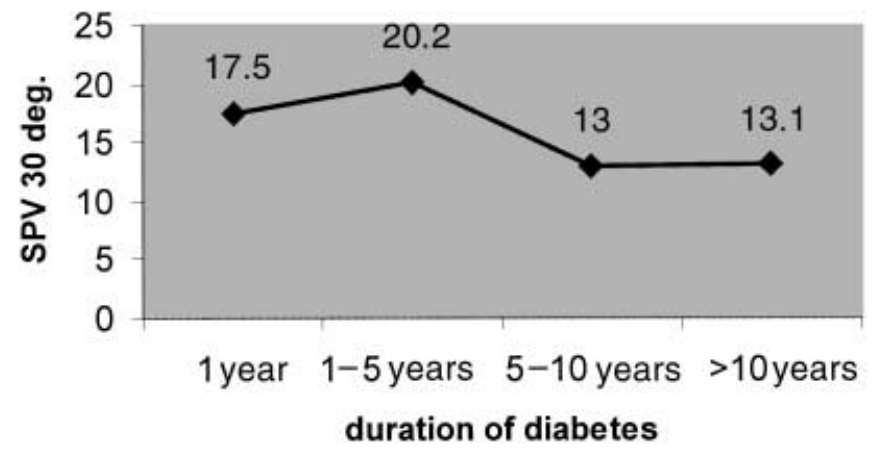

Fig. 3. Values of slow phase velocity of nystagmus (SPV) in relation to duration of diabetes in caloric test with water of temperature $30^{\circ} \mathrm{C} ; p<0.05$

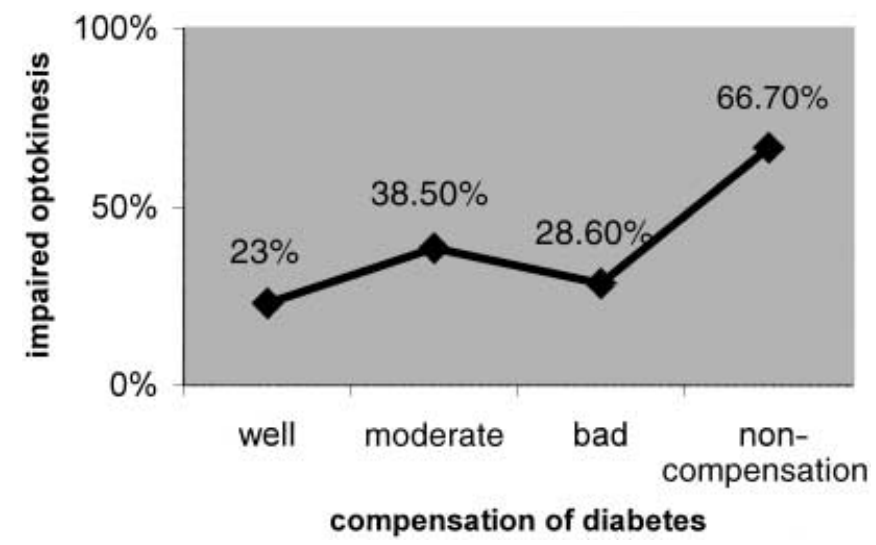

Fig. 4. Relation between optokinetic response and compensation of diabetes

open and closed as well as in positional nystagmus according to compensation of diabetes though the highest percentage of the disturbances was found in the subgroup with moderately compensated disease (Table 3).

Analysis of optokinetic reaction revealed an increase of pathological response in the subgroup with not compensated diabetes (Fig. 4).

There was an increase of pathological pattern in eye tracking test according to compensation of diabe- 


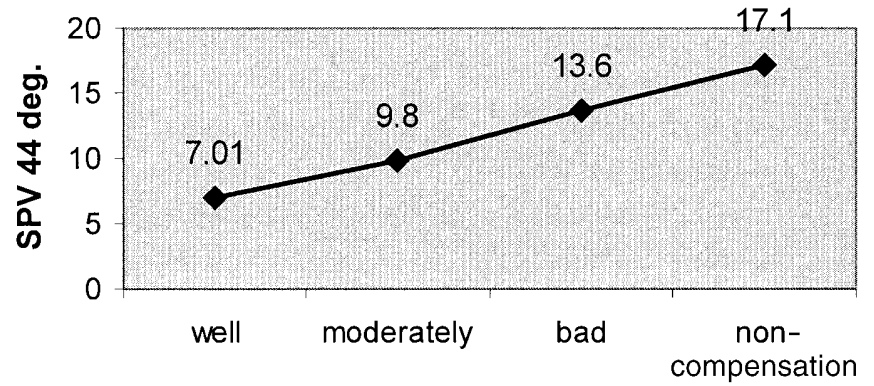

compensation of diabetes

Fig. 5. Relation between values of slow phase velocity of nystagmus and compensation of diabetes in caloric test with water of temperature $30^{\circ} \mathrm{C}(p<0.05)$. SPV $44 \mathrm{deg}$. - Slow-phase velocity of nystagmus in $\%$ in the test with water of temperature $44^{\circ} \mathrm{C}$
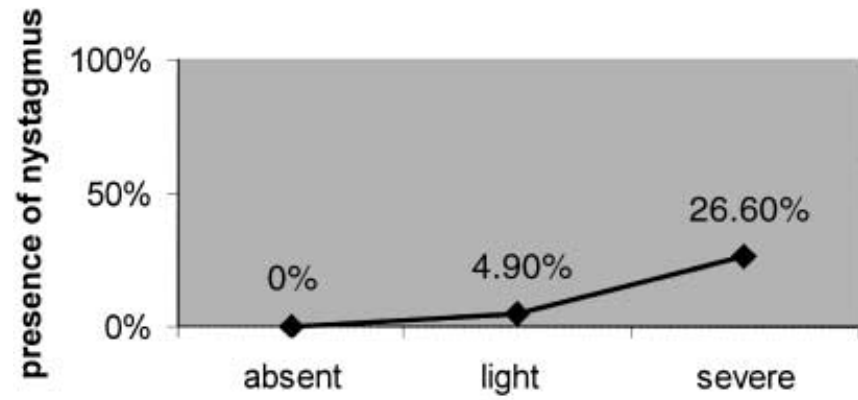

presence of hypoglycaemic incidents

Fig. 6. Relation between presence of spontaneous nystagmus and the presence and character of hypoglycaemic incidents $(p=0.001)$

tes. Slow-phase velocity of nystagmus induced in caloric test showed a tendency to increase according to the degree of diabetes compensation (Fig. 5).

The occurrence of spontaneous nystagmus measured with eyes closed increased in relation to the presence and character of hypoglycaemic incidents (Fig. 6).

Also the analysis of positional nystagmus revealed an important increase of disturbances, especially in the subgroups with serious hypoglycaemic incidents (Table 4).

The percentage of disturbances in optokinetic response and in eye tracking test increased markedly in subgroups with serious hypoglycaemic incidents (Table 5).

Slow-phase velocity of nystagmus induced in caloric tests was analysed according to hypoglycaemic incidents. Only in the test with water at a temperature of $30^{\circ} \mathrm{C}$, did the analysed values show a clear tendency to be reduced in the subgroup with serious hypoglycaemic incidents.

Particular analysis of spontaneous nystagmus, optokinetic response, eye tracking test and caloric response did not reveal any serious differences in the
Table 4. Relation between positional nystagmus and presence and character of hypoglycaemic incidents

\begin{tabular}{llll}
\hline $\begin{array}{l}\text { Type of } \\
\text { nystagmus }\end{array}$ & \multicolumn{2}{l}{ Hypoglycaemic incidents } \\
\cline { 2 - 4 } & $\begin{array}{l}\text { Hypoglycaemic } \\
\text { incidents } \\
\text { absent } \\
n=24\end{array}$ & $\begin{array}{l}\text { Minor } \\
\text { hypoglycaemic } \\
\text { incidents } \\
n=41\end{array}$ & $\begin{array}{l}\text { Severe } \\
\text { hypoglycaemic } \\
\text { incidents } \\
n=30\end{array}$ \\
\hline $\begin{array}{l}\text { Nylen I } \\
\text { Nylen II }\end{array}$ & - & $4.9 \%$ & $10.0 \%$ \\
Nylen III & $8.3 \%$ & - & $20.0 \%$ \\
Together & $8.3 \%$ & $2.0 \%$ & $23.3 \%$ \\
$p<0.001$ & & $6.9 \%$ & $53.3 \%$ \\
\hline
\end{tabular}

Table 5. Relation between optokinesis and eye tracking test and presence and character of hypoglycaemic incidents

\begin{tabular}{llll}
\hline & $\begin{array}{l}\text { Hypoglycaemia } \\
\text { absent } \\
n=24\end{array}$ & $\begin{array}{l}\text { Minor } \\
\text { hypoglycaemia } \\
n=41\end{array}$ & $\begin{array}{l}\text { Severe } \\
\text { hypoglycaemia } \\
n=30\end{array}$ \\
\hline $\begin{array}{l}\text { Impaired } \\
\text { optokinesis }\end{array}$ & $33.3 \%$ & $36.6 \%$ & $43.3 \%$ \\
$\begin{array}{l}\text { Improper } \\
\text { eye tracking } \\
\text { test }\end{array}$ & $33.3 \%$ & $31.7 \%$ & $39.9 \%$ \\
\hline
\end{tabular}

Table 6. Relation between electronystagmographic results and presence of diabetic complications

\begin{tabular}{lll}
\hline Parameter evaluated & $\begin{array}{l}\text { Complications } \\
\text { absent } \\
n=73\end{array}$ & $\begin{array}{l}\text { Complications } \\
\text { present } \\
n=22\end{array}$ \\
\hline $\begin{array}{lll}\text { Spontaneous nystagmus } \\
\text { Positional nystagmus }\end{array}$ & $7.5 \%$ & $13.6 \%$ \\
$\quad$ Nylen I & $4.1 \%$ & $9.09 \%$ \\
Nylen II & $6.84 \%$ & $4.54 \%$ \\
Nylen III & $8.21 \%$ & $18.1 \%$ \\
Together & $19.5 \%$ & $31.73 \%$ \\
Impaired optokinesis & $38.3 \%$ & $36.3 \%$ \\
Impaired eye tracking test & $34.26 \%$ & $36.35 \%$ \\
SPV 44 & $12.6 \% \mathrm{~s}$ & $11.6 \% \mathrm{~s}$ \\
SPV 30 & $16.9 \% \mathrm{~s}$ & $16.3 \% \mathrm{~s}$ \\
\hline
\end{tabular}

subgroups evaluated. However there was a distinct increase of disturbances in relation to spontaneous nystagmus with eyes closed and in the eye tracking test (Table 6).

\section{Discussion}

Functional evaluation of the vestibular organ in children is difficult and not often done. Not obvious interpretation of electronystagmographic records in children often states a problem. The electronystagmo- 
graphic pattern in our material, especially in children under 10 years of age, was characterised by high amplitude and interrupted by many symptoms like accessory eyeball movements or flutter provoked by restless behaviour of the child. The results of our studies indicate that metabolic disturbances present in diabetes provoke disturbances within the vestibular organ in those patients, though almost in all the cases the changes are not apparent clinically. In our group there were only six $(6.3 \%)$ patients, who complained about vertigo or balance disturbances or both while there were considerable disturbances in the laboratory tests within all the diabetic group in comparison to the control group. The disturbances in electronystagmography were of the central type mostly. They were reflected by impaired optokinetic response, improper eye tracking test and positional nystagmus Nylen type I and type III in patients with non-compensated diabetes and in the subgroups with serious hypoglycaemic incidents. Peripheral disturbances such as partial canal paresis occurred only in four $(4.22 \%)$ cases, positional nystagmus Nylen type II in $6(6.31 \%)$ cases. An increase of nystagmus slow phase velocity in the diabetic group in comparison to the control group in the test with water of temperature $44^{\circ} \mathrm{C}$ could be caused by generally increased reflexibility of vestibular organ in diabetic patients, perhaps resulting from improper processes of central reaction inhibition. Analysis of the incidence and character of ENG disturbances in relation to duration of diabetes revealed a distinct increase of some abnormalities as the disease progressed. The incidence of positional nystagmus, especially Nylen type III increased markedly. It should be stressed that some of the patients suffering longer had all three kinds of positional nystagmus. Attention ought to be paid to the well-marked increase of pathological optokinetic response in patients with a longer history of the disease. The results could suggest progression of central type disturbances in relation to duration of the disease. Values of nystagmus slow-phase velocity in relation to duration of the disease need to be interpreted. There was an increase of nystagmus slow-phase velocity in the test with water of temperature $30^{\circ} \mathrm{C}$ in the subgroup suffering from 1 to 5 years in comparison to patients suffering longer. Such results could result from decreasing reflexibility of vestibular organ with age. Analysis of electronystagmographic results according to the compensation of the disease did not reveal any important changes in relation to spontaneous and positional nystagmus. In comparison to other subgroups, there was a distinct increase of pathological recordings in optokinetic and eye tracking tests in the subgroup with non-compensated diabetes. Hyperglycaemia seems to provoke vestibular disturbances mostly of central localisation. Analysis of electronystagmographic results according to the presence and character of hypoglycaemic incidents revealed a higher percentage of the cases with spontaneous and positional [Nylen type III] nystagmus present in the subgroup with serious hypoglycaemic incidents. Moreover there was plain increase of pathological eye tracking test patterns in this subgroup. There was a slight tendency of nystagmus slow-phase velocity to decrease in the subgroups with more serious hypoglycaemic incidents.

Electronystagmographic analysis according to the presence of diabetic complications revealed a little higher percentage of disturbances in the subgroup with the complications present in relation to spontaneous nystagmus with eyes closed and eye tracking test. The lack of remarkable disturbances in electronystagmography in the subgroup with complications seems to results from the fact the complications were not very much advanced. Among 22 patients belonging to this subgroup there were only 2 diagnosed with polyneuropathy, the other 20 presented variously intensified retinopathy and/or nephropathy. Considering that $25 \%$ of the patients with diabetes develop complications after 10 years of the disease the potential percentage of the patients with subclinical neuropathy is small. The subgroup with the complications need to be further monitored.

Another problem is an attempt to compare vestibular organ condition to hearing organ condition in diabetic patients. One has to state there were certain disturbances in central auditory system though there were no any correlation between parameters characterising diabetes and BAEP results in diabetic patients. Considering that fact vestibular tests applied in the studies seem to be more sensitive for disturbances present in diabetes than auditory tests. Probably this results from a certain "dispersion" of vestibular organ within nervous system in relation to auditory organ. Metabolic disturbances could affect delicate homeostasis of vestibular organ more quickly than auditory organ.

Some authors observe technical problems of electronystagmographic examination procedure in younger children [8]. Lack of child's co-operation, numerous symptoms, changing reflexibility of the vestibular organ in children often handicap objective and completely repeatable evaluation of electronystagmographic records [9]. However, most authors agree it is possible to perform full battery of standard electronystagmographic tests in children over 4 years of age and to apply the same interpretation criteria as in adults $[10,11,12]$.

Negative influence of metabolic disturbances in diabetes mellitus on inner ear function was confirmed by many authors mostly in relation to cochlear part but to some extent to vestibular part of the labyrinth as well as in the context of vast structural and functional connections with other parts of central and peripheral nervous system $[13,14,15,16]$. But in general the literature concerning vestibular disturbances in diabetes is sparse. In 1977 it was suggested glucose 
metabolism disturbances might be responsible for vestibular organ problems [17]. However, the influence of diabetes mellitus on vestibular organ as well as diagnostic and therapeutic implications arising from this fact seem to be still an open matter. Some reports show an improper electronystagmographic results in $50 \%$ of diabetic patients without any subjective symptoms [4]. Nevertheless the authors showed a correlation between electronystagmographic disturbances and duration of diabetes, positive correlation between electronystagmographic disturbances and diabetic complications and no correlation between electronystagmographic results and glycated haemoglobin concentration [4]. Similar to our results the disturbances were mostly of central type. Other authors notice both central and peripheral changes in electronystagmography of the patients suffering from diabetes [18, 19]. The influence of hypoglycaemic incidents on vestibular organs of diabetic patients is another problem. Some authors state that longer or shorter periods of hypoglycaemia have an important influence on diabetic encephalopathy occurrence [20]. Those results are inconsistent with data of other authors who did not show any correlation of electronystagmographic disturbances and hypoglycaemic incidents $[4,18,19]$.

Many authors revealed disturbances in neural conduction within the brainstem in patients with Type I diabetes even in the case of normal pure tone audiometry, [21, 22, 23, 24]. It has been suggested there was an elongation of peak I latency in 93\% of diabetic children and an elongation of peak III latency in $73 \%$ of the cases [21]. The authors reported worse results in children with shorter history of the disease. Other authors showed abnormal values of BAEP latencies and interlatencies (peaks: I, III, V, I-III, I-V) in $48 \%$ of the patients with Type I diabetes but without any correlation with clinical and biochemical parameters characterising diabetes [22]. The latest results provide similar conclusions $[25,26]$. But there are also reports showing no disturbances in peripheral and central hearing organ in diabetes $[14,27,28]$.

The results obtained show complex pathophysiology of diabetes mellitus as well as individual course of the disease in individual patients. Certainly not all aspects and possibilities of vestibular organ diagnostic possibilities were used in this study. An attempt to localise the disturbances more precisely would be especially interesting. Nevertheless together with other interdisciplinary tests vestibular organ examination could give some information about the presence of complications of the disease as well as help to monitor diabetes.

Considering the results obtained one can conclude vestibular organ evaluation in children to be difficult. The assessment requires deep clinical experience and mostly, individual attitude to the patients. Metabolic disturbances present in Type I diabetes cause disturbances in different parts of the vestibular organ but mostly in its central part. The range of vestibular organ impairment in Type I diabetes seems to depend on the presence and character of hypoglycaemic incidents and the duration of the disease mainly and on the compensation of diabetes to some extent. Though the disturbances are present both in central vestibular and hearing organs in diabetes the evaluation of the first one seems to be more specific in detecting early disturbances present within central nervous system. Probably it would be reasonable to monitor vestibular organ condition, especially in young people with diabetes mellitus.

\section{References}

1. Yagihashi S (1995) Pathology and pathogenetic mechanisms of diabetic neuropathy. Diabetes Metab Rev 11: 193-225

2. Vinik AI, Liuzze FJ, Holland MT, Stansberry KB, Le Beau JM, Colen LB (1992) Diabetic neuropathies. Diabetes Care 15: $1926-1975$

3. Smith TL, Raynor E, Prazma J, Buenting JE, Pillsbury HC (1995) Insulin-dependent diabetic microangiopathy in the inner ear. Laryngoscope 105: 236-240

4. Biurrun O, Ferrer JP, Lorente J, De Espana R, Gomis R, Traserra J (1991) Asymptomatic electronystagmographic abnormalities in patients with type I diabetes mellitus. ORL 53: 335-338

5. McQueen CT, Baxter A, Smith TL et al. (1999) Noninsulin-dependent diabetic microangiopathy in the inner ear. J Laryngol Otol 113: 13-18

6. Rust KR, Prazma J, Triana RJ, Michaelis OE 4th (1992) Inner ear damage secondary to diabetes mellitus. Arch Otolaryngol Head Neck Surg 118: 42-53

7. Triana RJ, Suits GW, Garrison S (1991) Inner ear damage secondary to diabetes mellitus I. Changes in aging SHR/ N-cp rats. Arch Otolaryngol Head Neck Surg 117: 635-640

8. Cyr DG, Brookhouser PE, Maureen V, Grossman A (1985) Vestibular evaluation of infants and preschool children. Otolaryngol Head Neck Surg 93: 463-468

9. Pospiech L (1991) Difficulties in otoneurologic diagnosis in children. Otolaryngol Pol 45 [Suppl.]: 250-252

10. Eviatar L, Eviatar A (1974) Vertigo in childhood comments on pathogenesis and managements. Clin Pediatr (Phil) 13: 940-941

11. Eviatar L, Eviatar A (1978) Neurovestibular examination of infants and children. Adv Otorhinolaryngol 23: 169-191

12. Brzezinska H, Gryczynska D, Andrzejewski J, Grodecki W, Zelazowska E (1984) Dizzy child. Otolaryng Pol 38 [Suppl.]: 391-393

13. Myers SF, Ross MD (1987) Morphological evidence of vestibular pathology in long-term experimental diabetes mellitus. Acta Otolaryngol (Stockh) 104: 40-49

14. Filipo R, De Seta E, Bertoli A (1985) High-frequency audiometry in juvenile diabetes. Adv Audiol 3: 106-111

15. Tooke JE (1987) The microcirculation in diabetes. Diabet Med 4: 189-196

16. Wackym PA, Linthicum FH (1986) Diabetes mellitus and hearing loss: Clinical and histopathologic relationships. Am J Otol 7: 176-182

17. Updegraff WR (1977) Impaired carbohydrate metabolism in idiopathic Meniere's disease. Ear Nose Throat J 56: $160-163$ 
18. Aantaa E, Lehtonen A (1981) Electronystagmographic findings in insulin-dependent diabetics. Acta Otolaryngol (Stockh) 91: 15-18

19. Virtaniemi J, Laakso M, Nuutinen J, Karjalainen S, Vartiainen E (1993) Voluntary eye movement tests in patients with insulin-dependent diabetes mellitus. Acta Otolaryngol (Stockh) 113: 123-127

20. Jaspan JB, Wollman RL, Bernstein L, Rubinstein AH (1982) Hypoglcemic peripheral neuropathy in association with insulinoma: implication of glucopenia rather than hyperinsulinism. Case report and literature review. Medicine (Baltimore) 61: 33-44

21. Niedzielska G, Katska E (1998) ABR disturbances in children with insulin dependent diabetes mellitus. Int Pediatr Otorhinolaryngol 44: 1-4

22. Obrebowski A, Pruszewicz A, Gawlinski M, Swidzinski P (1999) Electrophysiological hearing examinations in children and youngsters with insulin dependent diabetes. Otolaryngol Pol 5: 595-598

23. Obrebowski A, Pruszewicz A, Swidzinski P, ObrebowskaKarsznia Z, Karlik M, Gawlinski M (1999) The electro- physiolgical examinations of hearing in some metabolic disorders. Otolaryngol Pol 5: 591-593

24. Orendorz-Fraczkowska K, Gawron W, Pospiech L, Noczynska A (2001) Brainstem auditory evoked potentials in children and adolescenst with diabetes mellitus type 1 . Diabetol Pol 8: 178-182

25. Lisowska G, Namyslowski G, Morawski K, Strojek K (2001) Early identification of hearing impairment in patients with type 1 diabetes mellitus. Otol Neurotol 20: 2316-2320

26. Tóth F, Varkonyi TT, Kiss JG et al. (2001) Brainstem auditory-evoked potential examinations in diabetic patients. Scand Audiol Suppl 52: 156-159

27. Goldsher M, Pratt H, Hassan A, Shenhav R, Eliacher I, Kanter Y (1986) Auditory brainstem evoked potentials in insulin-dependent diabetics with and without peripheral neuropathy. Acta Otolaryngol 102: 204-208

28. Hendriks JJT, DeJong RN, Hogenhus LAA (1985) Investigations of retrocochlear function in diabetic neuropathy. Clin Otolaryngol 10: 51 